\title{
Electric Drive Control with Rotor Resistance and Rotor Speed Observers Based on Fuzzy Logic
}

\author{
C. Ben Regaya, A. Zaafouri, and A. Chaari \\ Unit C3S, High National School of Engineers of Tunis (ESSTT), University of Tunis, 5 Avenue Taha Hussein, \\ BP 56, 1008 Tunis, Tunisia \\ Correspondence should be addressed to C. Ben Regaya; chiheb_ben_regaya@yahoo.fr
}

Received 10 September 2013; Revised 19 November 2013; Accepted 19 November 2013; Published 16 February 2014

Academic Editor: Hui Zhang

Copyright (c) 2014 C. Ben Regaya et al. This is an open access article distributed under the Creative Commons Attribution License, which permits unrestricted use, distribution, and reproduction in any medium, provided the original work is properly cited.

Many scientific researchers have proposed the control of the induction motor without speed sensor. These methods have the disadvantage that the variation of the rotor resistance causes an error of estimating the motor speed. Thus, simultaneous estimation of the rotor resistance and the motor speed is required. In this paper, a scheme for estimating simultaneously the rotor resistance and the rotor speed of an induction motor using fuzzy logic has been developed. We present a method which is based on two adaptive observers using fuzzy logic without affecting each other and a simple algorithm in order to facilitate the determination of the optimal values of the controller gains. The control algorithm is proved by the simulation tests. The results analysis shows the characteristic robustness of the two observers of the proposed method even in the case of variation of the rotor resistance.

\section{Introduction}

Induction motors are broadly used in industrial applications and the majority of power in the world is currently consumed by them. They are used because of their benefits compared to other types of rotating electrical machines, such as robustness, reliability, and reduced maintenance [1]. Many methods of control presented in the literature have been proposed to circumvent the problem of variation of the rotor resistance for the indirect field-oriented controlled induction machines, which can change with time due to ohmic heating [2]. Among these methods, we can mention the adaptive control using an adaptive scheme of the rotor resistance [3, 4], identification of rotor resistance based on Lyapunov stabilization theory [5], and estimator based on fuzzy logic [6-8]. In these studies, estimation and adaptation mechanisms have been used with the sole aim to correct the rotor resistance used as a reference value in the calculation of the slip frequency. To know the exact position of the rotor flux, the estimation block of the slip angular speed will be used by the control algorithm. Following the research done in this field shows that the performance of the control for the induction motor drive depends heavily on the precision with which the motor parameters are known in particular the rotor resistance. Its mismatch affects significantly the open loop slip estimator and degrades the performance of the speed control, especially when the machine is loaded [3-6].

In addition to the adaptive control of the vector control with rotor resistance adaptation, other works have proposed the speed sensorless control [9-14]. The elimination of speed sensors has become an inevitable task to guarantee the high performance control and operating reliability, not only because the sensors increase the cost and complexity of machines, but also the measures are stained by the noise that affects the robustness of control, especially in hostile environments. Various technical controls without speed sensor were presented in this research, such as adaptive speed observer [9], MRAS speed estimator [10, 11], fuzzy logic speed observer [12], and backstepping and sliding mode speed observer [13, $14]$.

A variation of the rotor resistance will cause an error of estimating the rotor speed [3]. To overcome this drawback, simultaneous estimation of the motor speed and the rotor resistance is required $[15,16]$. In this paper, a solution based on the theory of the fuzzy logic is developed. The method will allow the estimation of rotor resistance and reinject it in the 
control loop in order to guarantee the decoupling between the torque and flux dynamics. This solution will guarantee a good estimation of the slip frequency even in the case of variations in the rotor resistance. For the speed estimation we have used the model reference adaptive system MRAS observer which is based on fuzzy logic. Therefore, we have two observers which use fuzzy logic without interacting with each other. This paper presents the steps to be followed for the development of simultaneous estimation of the rotor resistance and rotor speed using two types of observer based on fuzzy logic.

First we are going to present the mathematical model of the induction motor in Section 2. Section 3 is dedicated to present the indirect field-oriented control technique. Then we are going to describe the steps of designing the fuzzy logic observer of the rotor resistance. The fuzzy logic MRAS speed estimation and the algorithm to determine the optimal values of the controller gains are developed in Section 5. Finally, simulations are presented in the last section using Matlab environment with some comments to conclude this work.

\section{Induction Motor Modeling}

The mathematical model of the induction motor can be described in the reference frame connected to the rotating field as follows $[5,12]$

$$
\begin{aligned}
\frac{d}{d t}\left[\begin{array}{l}
i_{s} \\
\phi_{r}
\end{array}\right] & =\left[\begin{array}{ll}
A_{11} & A_{12} \\
A_{21} & A_{22}
\end{array}\right]\left[\begin{array}{c}
i_{s} \\
\varphi_{r}
\end{array}\right]+\left[\begin{array}{r}
B_{1} \\
0
\end{array}\right] v_{s}, \\
i_{s} & =C\left[\begin{array}{c}
i_{s} \\
\varphi_{r}
\end{array}\right],
\end{aligned}
$$

where

$$
\begin{aligned}
& i_{s}=\left[\begin{array}{ll}
i_{s d} & i_{s q}
\end{array}\right]^{T}: \text { stator current, } \\
& \phi_{r}=\left[\begin{array}{ll}
\varphi_{r d} & \varphi_{r q}
\end{array}\right]^{T}: \text { rotor flux, } \\
& v_{s}=\left[\begin{array}{ll}
v_{s d} & v_{s q}
\end{array}\right]^{T}: \text { stator voltage, } \\
& A_{11}=-\left(\left(R_{s} / \sigma L_{s}\right)+\left(R_{r}(1-\sigma) / \sigma L_{r}\right)\right) I-\omega_{s} J \text {, } \\
& A_{12}=\left(L_{m} / \sigma L_{s} L_{r}\right)\left[\left(R_{r} / L_{r}\right) I-\omega_{r} J\right] \text {, } \\
& A_{21}=\left(L_{m} / \tau_{r}\right) I, A_{22}=\left(\omega_{s}-\omega_{r}\right) J-\left(1 / \tau_{r}\right) I, B_{1}= \\
& \left(1 / \sigma L_{s}\right) I \text {, } \\
& C=\left[\begin{array}{ll}
I & 0_{2 \times 2}
\end{array}\right], I=\left[\begin{array}{ll}
1 & 0 \\
0 & 1
\end{array}\right], J=\left[\begin{array}{cc}
0 & -1 \\
1 & 0
\end{array}\right] \text {, } \\
& R_{r}, R_{s} \text { : stator and rotor resistance, } \\
& L_{s}, L_{r} \text { : stator and rotor self-inductance, } \\
& L_{m}: \text { mutual inductance, } \\
& \sigma \text { : leakage coefficient, } \\
& \tau_{r} \text { : rotor time constant, } \\
& \omega_{s} \text { : stator angular frequency, } \\
& \omega_{r} \text { : motor angular velocity (electric angle). }
\end{aligned}
$$

The electromagnetic torque developed by the machine is expressed by

$$
T_{\mathrm{em}}=\frac{3}{2} \frac{L_{m} n_{p}}{L_{r}}\left(\varphi_{r d} i_{s q}-\varphi_{r q} i_{s d}\right) .
$$

\section{Indirect Field-Oriented Control of Induction Motor Drive (IFOC)}

Two recommended techniques for controlling the induction motor with high performance have been presented in the literature. The first one is called direct field-oriented control (DFOC) and the second one is the indirect field-orientated control (IFOC) [1]. In order to optimize the performance of the induction motor and reduce the sensitivity of the stability of the device for controlling the variation of rotor resistance, we will use the indirect field-oriented control technique. The main objective of this control strategy is, as in DC machines, to independently control the torque and the flux; this is done by using a $d-q$ rotating reference frame synchronously with the rotor flux space vector $[2,3]$. In ideal field-oriented control, the rotor flux linkage axis is forced to align with the $d$-axes, and it follows that

$$
\begin{gathered}
\varphi_{r q}=\frac{d}{d t} \varphi_{r q}=0, \\
\varphi_{r d}=\varphi_{r} .
\end{gathered}
$$

Applying the result of (3), the torque equation becomes analogous to the DC machine and can be described as follows:

$$
T_{\mathrm{em}}=\frac{3}{2} \frac{L_{m} n_{p}}{L_{r}} \varphi_{r d} i_{s q} .
$$

The relationship of mechanical speed and the angular velocity of rotating reference frame $d-q$ is given by the following equation:

$$
\omega_{s}=\frac{L_{m} R_{r}}{L_{r} \varphi_{r d}} i_{s q}+n_{p} \omega_{r} .
$$

\section{Strategy for Estimating the Rotor Resistance Using Fuzzy Logic Method}

From (1), in steady-state the dynamic of the rotor fluxes can be expressed as follows:

$$
\begin{gathered}
\varphi_{r d}=\frac{R_{r} L_{m}}{L_{r}}\left(\frac{L_{r}}{R_{r}} i_{s d}+\frac{L_{r}^{2}}{R_{r}^{2} L_{m}}\left(\omega_{s}-\omega_{r}\right) \varphi_{r q}\right), \\
\varphi_{r q}=\frac{R_{r} L_{m}}{L_{r}}\left(\frac{L_{r}}{R_{r}} i_{s q}-\frac{L_{r}^{2}}{R_{r}^{2} L_{m}}\left(\omega_{s}-\omega_{r}\right) \varphi_{r d}\right) .
\end{gathered}
$$

By replacing $\varphi_{r d}, \varphi_{r q}$ with expressions (1), (6) becomes

$$
\begin{gathered}
\varphi_{r d}=\frac{\left(L_{m} R_{r} / L_{r}\right)\left(\left(R_{r} / L_{r}\right) i_{s d}+\left(\omega_{s}-\omega_{r}\right) i_{s q}\right)}{\left(R_{r} / L_{r}\right)^{2}}+\left(\omega_{s}-\omega_{r}\right)^{2}, \\
\varphi_{r q}=\frac{\left(L_{m} R_{r} / L_{r}\right)\left(\left(R_{r} / L_{r}\right) i_{s q}-\left(\omega_{s}-\omega_{r}\right) i_{s d}\right)}{\left(R_{r} / L_{r}\right)^{2}}+\left(\omega_{s}-\omega_{r}\right)^{2} .
\end{gathered}
$$

The angular velocity is expressed as follows:

$$
\left(\omega_{s}-\omega_{r}\right)^{*}=\omega_{g}^{*}=\frac{R_{r}^{*} i_{s q}^{*}}{L_{r}^{*} i_{s d}^{*}},
$$

where $(*)$ means reference. 


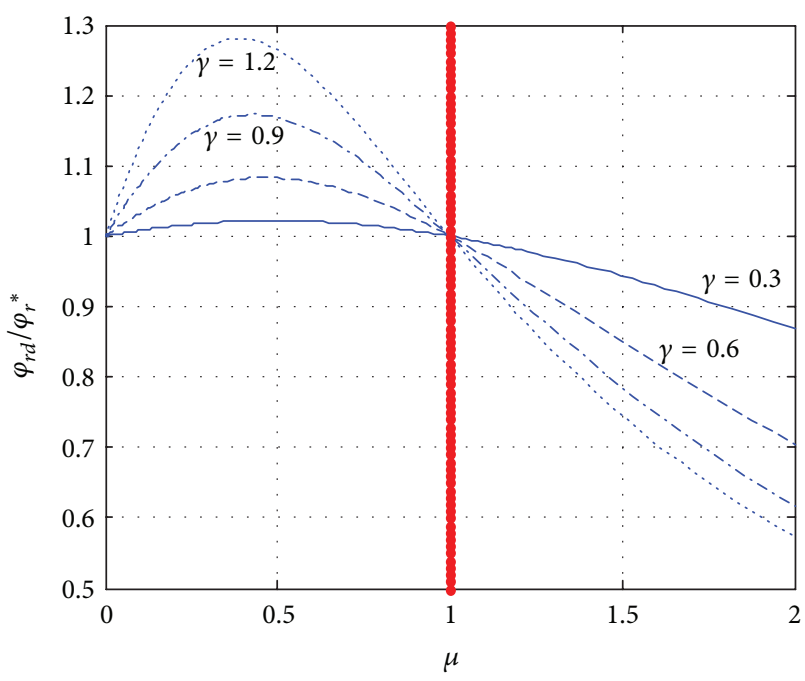

FIGURE 1: Effect of variation of the rotor resistance on the shape of the direct flux.

So the expressions of flux along the two axes become

$$
\begin{gathered}
\varphi_{r}^{*}=\varphi_{r d}^{*}=L_{m} i_{s d}^{*}, \\
\varphi_{r q}^{*}=0 .
\end{gathered}
$$

Equation (9) is considered as a reference model for the mechanism of adjusting the rotor resistance by fuzzy logic. Assuming that the rotor resistance changes from its nominal value $R_{r n}$ to $R_{r n}+\Delta R_{r}$ and $k_{R r}$ is the factor for this variation we get

$$
k_{R r}=\frac{R_{r}}{R_{r n}}=\frac{1}{\mu},
$$

with $\mu=R_{r n} / R_{r}$.

By replacing the expression of $\mu$ in (7) we will have

$$
\begin{gathered}
\varphi_{r d}=\frac{L_{m} i_{s d}+L_{m} i_{s d} \mu \gamma^{2}}{1+(\mu \gamma)^{2}}, \\
\varphi_{r q}=\frac{L_{m} i_{s d} \gamma(1-\gamma)}{1+(\mu \gamma)^{2}},
\end{gathered}
$$

with $\gamma=i_{s q} / i_{s d}$.

Finally, the flux components can be expressed in terms of the reference flux for an ideal decoupling as follows:

$$
\begin{aligned}
& \frac{\varphi_{r d}}{\varphi_{r}^{*}}=\frac{1+\mu \gamma^{2}}{1+(\mu \gamma)^{2}}, \\
& \frac{\varphi_{r q}}{\varphi_{r}^{*}}=\frac{\gamma(1-\gamma)}{1+(\mu \gamma)^{2}} .
\end{aligned}
$$

Figures 1 and 2 show the shape of $\varphi_{r d} / \varphi_{r}^{*}$ and $\varphi_{r q} / \varphi_{r}^{*}$ as a function of $\mu$, and the vertical line in color red represents the ideal orientation of the rotor flux.

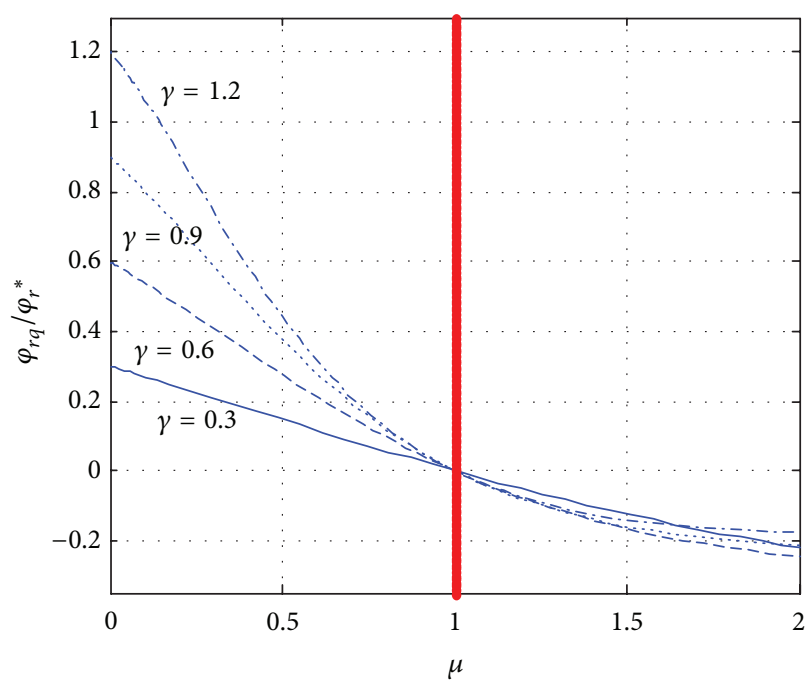

FIGURE 2: Effect of variation of the rotor resistance on the shape of the quadratic flux.

$\gamma$ is a parameter that reflects the power of the induction motor. The vertical line is the ideal orientation of the flux. We identify changes in flux along the two axes of the rotating frame $d-q$ as follows:

$$
\begin{gathered}
\Delta \varphi_{r d}=\varphi_{r}^{*}-\varphi_{r d}, \\
\Delta \varphi_{r q}=-\varphi_{r q} .
\end{gathered}
$$

According to Figures 1 and 2 we can see that

(i) for $\mu>1$, there is reduced flux along the two axes,

(ii) for $\mu<1$, there is increased flux along the two axes.

According to (9), we can write

(i) for $\mu>1, \Delta \varphi_{r d}>0$ and $\Delta \varphi_{r q}>0$,

(ii) for $\mu<1, \Delta \varphi_{r d}<0$ and $\Delta \varphi_{r q}<0$.

Since $\mu=R_{r n} / R_{r}$, so we can write the rules of the adaptive fuzzy logic mechanism of the rotor resistance $R_{r}$ as follows:

(i) for $\mu>1 \Leftrightarrow R_{r}<R_{r n}$, we have $\Delta \varphi_{r d}>0$ and $\Delta \varphi_{r q}>$ 0 ,

(ii) for $\mu<1 \Leftrightarrow R_{r}>R_{r n}$, we have $\Delta \varphi_{r d}<0$ and $\Delta \phi_{r q}<$ 0 .

The block diagram of the fuzzy logic adaptation mechanism used in our simulation is given in Figure 3.

The estimated fluxes $\widehat{\varphi}_{r d}$ and $\widehat{\varphi}_{r q}$ can be obtained by measuring the currents and stator voltages. First we will estimate the stator flux using the following equations:

$$
\left[\begin{array}{l}
\varphi_{s d} \\
\varphi_{s q}
\end{array}\right]=\left[\begin{array}{cc}
\cos \left(\theta_{s}\right) & \sin \left(\theta_{s}\right) \\
-\sin \left(\theta_{s}\right) & \cos \left(\theta_{s}\right)
\end{array}\right]\left[\begin{array}{c}
\varphi_{s \alpha} \\
\varphi_{s \beta}
\end{array}\right],
$$

with

$$
\begin{aligned}
& \varphi_{\alpha s}=\int\left(v_{s \alpha}-R_{s} i_{s \alpha}\right) d t, \\
& \varphi_{\beta s}=\int\left(v_{s \beta}-R_{s} i_{s \beta}\right) d t .
\end{aligned}
$$




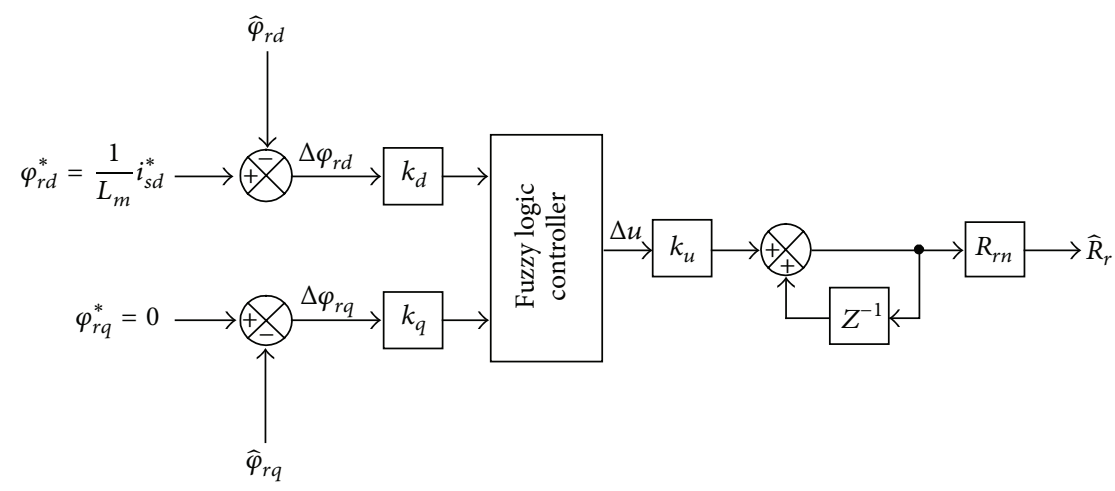

FIGURE 3: Block diagram of the adaptation mechanism of rotor resistance using fuzzy logic.

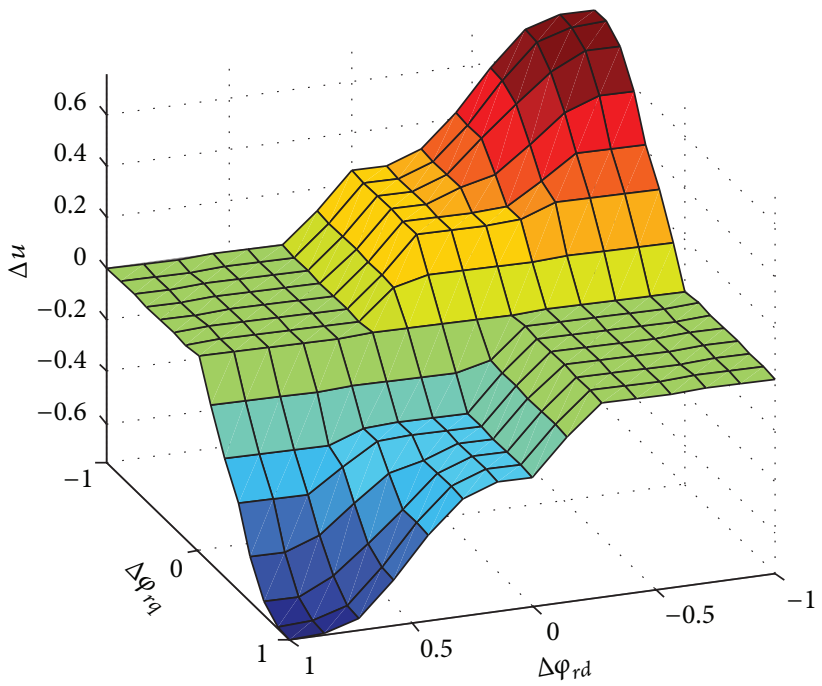

FiguRE 4: Variation law of fuzzy controller for the rotor resistance.

Then we can calculate the estimated flux by the following equation:

$$
\left[\begin{array}{l}
\widehat{\varphi}_{r d} \\
\widehat{\varphi}_{r q}
\end{array}\right]=\left[\begin{array}{cc}
\frac{L_{r}}{L_{m}} & 0 \\
0 & \frac{L_{r}}{L_{m}}
\end{array}\right]\left[\begin{array}{l}
\varphi_{s d} \\
\varphi_{s q}
\end{array}\right]-\left[\begin{array}{cc}
\frac{L_{r} L_{s} \sigma}{L_{m}} & 0 \\
0 & \frac{L_{r} L_{s} \sigma}{L_{m}}
\end{array}\right]\left[\begin{array}{l}
i_{s d} \\
i_{s q}
\end{array}\right]
$$

When choosing the linguistic value it should be taken into account that the control must be robust and time of calculation adopted by the fuzzy controller should not be high to not slow down the process $[6,7]$. In this proposed method linguistic value of 5 is chosen which gives 25 rules.

For fuzzification, we have chosen triangular fuzzification and for deffuzzification the centroid deffuzzification method is used in the proposed method. The universe of discourse is common to all fuzzy variables $\left(\Delta \varphi_{r d}, \Delta \varphi_{r q}\right.$, and $\left.\Delta_{u}\right)$ and is divided into seven fuzzy sets (NB, NM, NS, ZE, PS, PM, and $\mathrm{PB})$ with triangular membership functions.

In terms of numerical values, the behavior of this mechanism is characterized by action law shown in Figure 4. Indeed,
TABLE 1: Fuzzy control rules for calculating $\Delta u$.

\begin{tabular}{lccccccc}
\hline$\Delta \varphi_{r q}$ & & & \multicolumn{5}{c}{$\Delta \varphi_{r d}$} \\
& NB & NM & NS & ZE & PS & PM & PB \\
\hline NB & PB & PM & PS & PS & ZE & ZE & ZE \\
NM & PM & PS & PS & PS & ZE & ZE & ZE \\
NS & PS & PS & PS & PS & ZE & ZE & ZE \\
ZE & ZE & ZE & ZE & ZE & ZE & ZE & ZE \\
PS & ZE & ZE & ZE & NS & NS & NS & NS \\
PM & ZE & ZE & ZE & NS & NS & NS & NM \\
PB & ZE & ZE & ZE & NS & NS & NM & NB \\
\hline
\end{tabular}

for each pair of input values (Table 1)the mechanism generates a variation of the control law $(\Delta u)$, which corresponds to the increase or decrease of the rotor resistance.

\section{Fuzzy Logic MRAS Speed Observer Design}

In this section we will present the different steps to design the fuzzy logic MRAS speed observer. This method consists in comparing the output of both estimators. The first one 


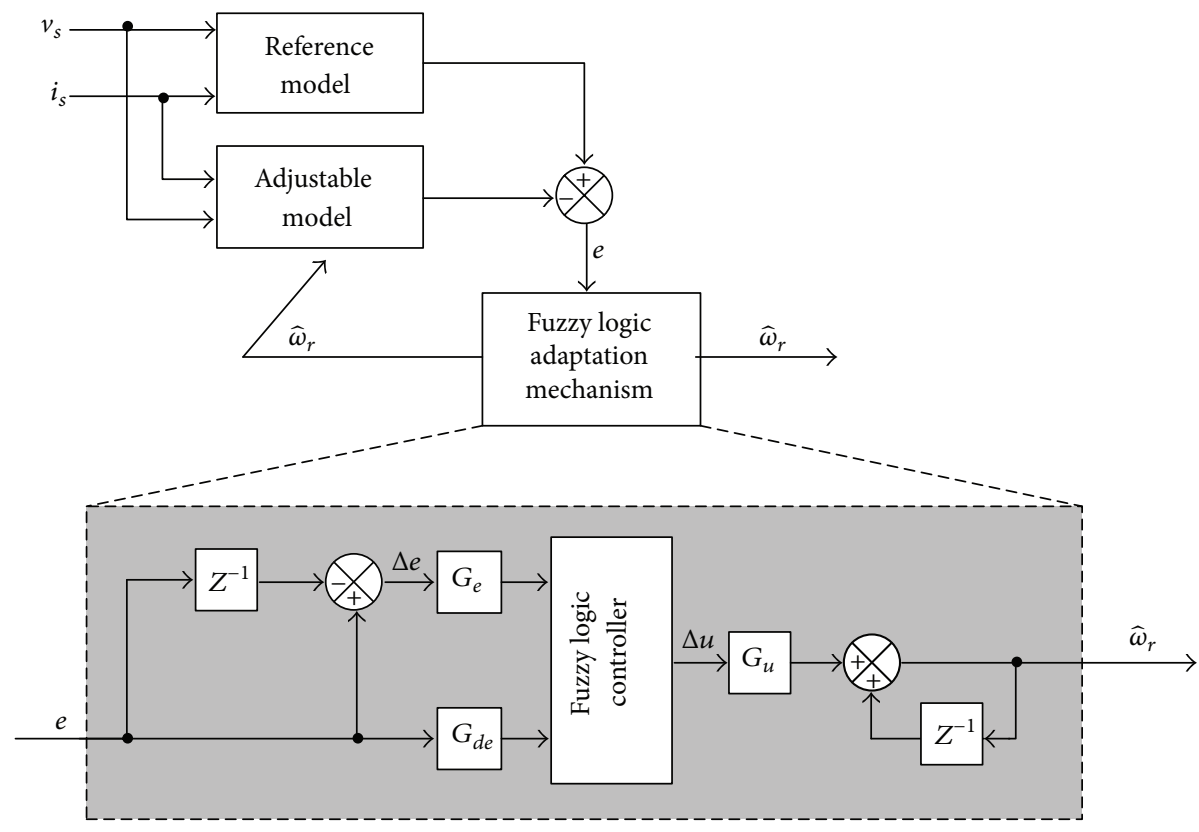

FIGURE 5: Block diagram of the fuzzy logic MRAS speed observer.

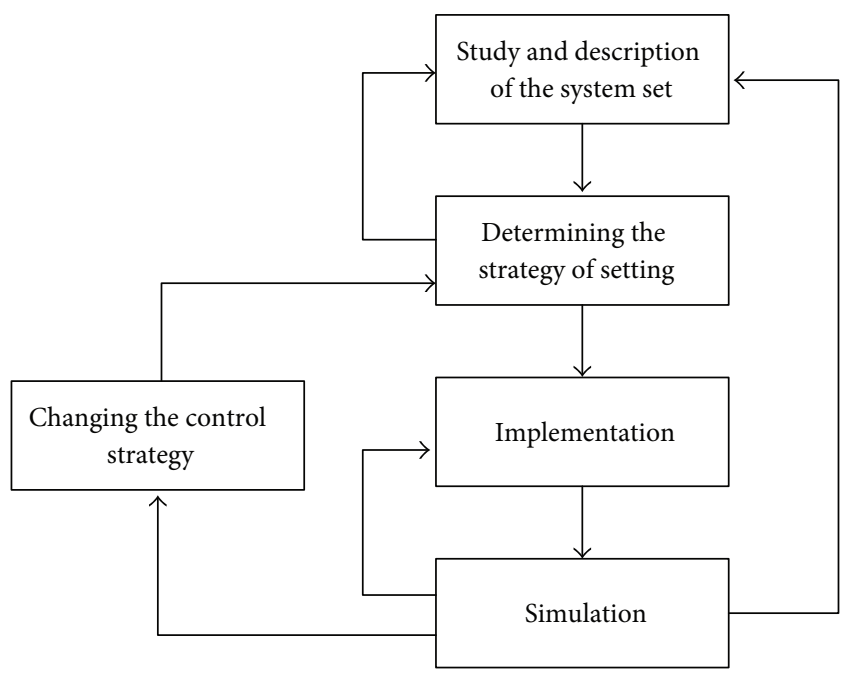

FIGURE 6: The steps for designing a fuzzy logic controller.

is called the reference model which is independent of the quantity to estimate, and the second is the adjustable model [10]. The error between the two estimators of the observing rotor flux is injected in an adaptation mechanism which can generate the value of $\omega_{r}$ as a way to minimize the error of flux.

The mechanism of adaptation is a fuzzy logic controller; the block diagram of the MRAS speed observer and the structure of the controller is shown in Figure 5.

The reference model is expressed by using the stator voltages and stator currents. Their components are expressed in a stationary frame when the flux components are generated.

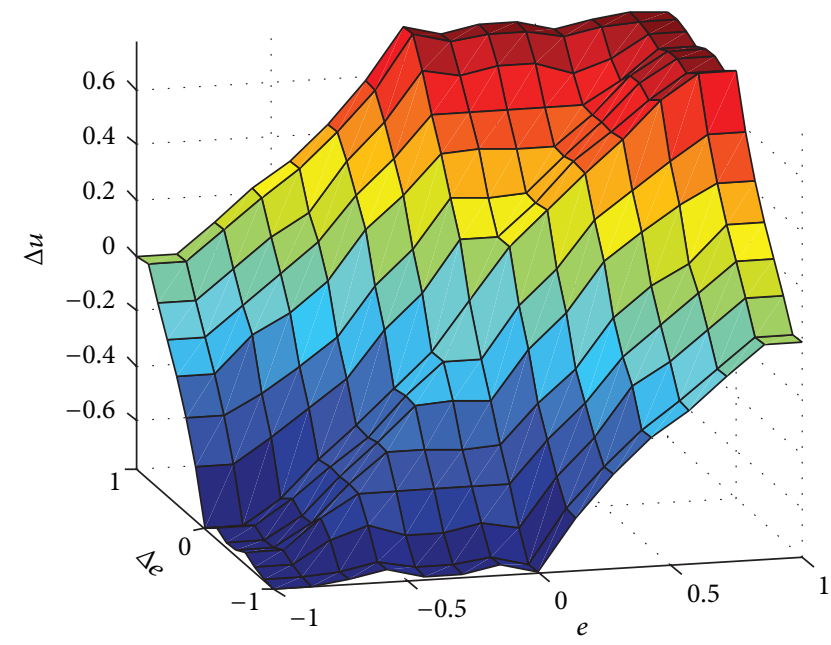

FIgURE 7: Variation law of fuzzy controller for MRAS speed observer.

The reference value of the rotor flux components is described by the following equation [3]:

$$
\begin{aligned}
& \frac{d}{d t} \varphi_{r d}=\frac{L_{r}}{L_{m}}\left(v_{s d}-R_{s} i_{s d}-\sigma L_{s} \frac{d}{d t} i_{s d}\right), \\
& \frac{d}{d t} \varphi_{r q}=\frac{L_{r}}{L_{m}}\left(v_{s q}-R_{s} i_{s q}-\sigma L_{s} \frac{d}{d t} i_{s q}\right) .
\end{aligned}
$$

The adaptive model describes the rotor equation and the rotor flux according to the $d$ - $q$ axes which are expressed as a 
function of the rotor speed and the stator currents. From (1), the adaptive model is described by the following equations:

$$
\begin{aligned}
& \frac{d}{d t} \widehat{\varphi}_{r d}=-\frac{R_{r}}{L_{r}} \widehat{\varphi}_{r d}-\widehat{\omega}_{r} \widehat{\varphi}_{r q}+\frac{L_{m} R_{r}}{L_{r}} i_{s d}, \\
& \frac{d}{d t} \widehat{\varphi}_{r q}=-\frac{R_{r}}{L_{r}} \widehat{\varphi}_{r q}+\widehat{\omega}_{r} \widehat{\varphi}_{r d}+\frac{L_{m} R_{r}}{L_{r}} i_{s q} .
\end{aligned}
$$

From (17) and (18), the adaptation mechanism can be designed to generate the estimated speed value which is used to minimize the error between the estimate and reference fluxes. The error between reference model and adjustable model $e$ is minimized by a fuzzy logic controller which generates the estimated speed. This signal $e$ is given by the following expression:

$$
e=\varphi_{r q} \widehat{\varphi}_{r d}-\varphi_{r d} \widehat{\varphi}_{r q}
$$

For the design of a fuzzy regulator we must, first, study the system to adjust and make an adequate description. It is not a proper analysis to establish a mathematical model. We must rather explore the behavior of the controlled system vis-à-vis changes in the control variable and determine measurable quantities characteristic of dynamic behavior. The description may make use of linguistic variables and must be accompanied by a definition of membership functions [12]. Then we move on to determining the control strategy that includes the fuzzification, inference, and deffuzzification. After implementation, most often on a PC or microprocessor software or hardware with processor autographed (specific processors for the fuzzy logic), testing the installation is usually necessary to change the control strategy interactively in several steps in order to find proper behavior. This change is highlighted by Figure 6, since it is an important step in the design of a fuzzy set.

The quality of adjustment depends not only on the rules but also on the choice of values with which the input and output variables are multiplied. To define the values of $G_{e}$, $G_{d e}$, and $G_{u}$ we use the following algorithm.

Step 1. Set the gains values of $G_{e}, G_{d e}$, and $G_{u}$ (in our case $G_{e}=1, G_{d e}=1$, and $\left.G_{u}=1\right)$.

Step 2. If the error $<1 \%$, go to Step 7 .

Step 3. Adjust $G_{e}$.

Step 4. If the error $>10 \%$, go to Step 3 .

Step 5. Adjust $G_{d e}$ and $G_{u}$.

Step 6. If the error $>1 \%$, go to Step 5 .

Step 7. End of algorithm.

The establishment of rules defining the output results from operating expertise. For our application, we used the basic rules given in Table 2, which stems from expertise and is based on the operating principle of the bang-bang that offers very good results. The latter is organized in the form
TABLE 2: Table fuzzy control rules $\Delta u$.

\begin{tabular}{llllll}
\hline$e / \Delta e$ & NB & NS & ZE & PS & PB \\
\hline NB & NB & NB & NB & NS & ZE \\
NS & NB & NB & NS & ZE & PS \\
ZE & NB & NS & ZE & PS & PB \\
PS & NS & ZE & PB & PB & PB \\
PB & ZE & PS & PB & PB & PB \\
\hline
\end{tabular}

of a decision table. The inference method used is the method (Max-Min) since it is easy to implement. The following table shows the rules that correspond to these reflections.

In the proposed method each variable of the fuzzy logic controller has five triangular membership functions. The fuzzy sets used in the proposed method are NB: Negative Big, NS: Negative Small, ZE: Zero Equal, PS: Positive Small, and PB: Positive Big. The variation law of fuzzy controller for MRAS speed observer is shown in Figure 7.

\section{Simulation Results and Discussion}

The performances of the proposed solution are evaluated using Matlab-Simulink. A dynamic three-phase induction motor model with speed and rotor resistance observer was built to emulate behavior of the motor. The three-phase induction motor parameters are given in Table 3 . Figure 8 shows the architecture of the vector control algorithm incorporating the fuzzy logic MRAS speed observer and rotor resistance fuzzy logic observer.

Figure 9 shows the effect of sudden change on the shape of direct and quadratic flux. At $t=2 \mathrm{~s}$ we introduced a $50 \%$ increase of the rotor resistance. Just at the moment of variation (Figure 9(a)) the orientation of the fluxes is lost, which has a negative effect on the control. Using an estimate of the rotor resistance by the fuzzy logic guarantees the orientation of flux (Figure 9(b)).

Figure 10 shows the evolution of the real and estimated rotor resistance. When increasing the value of the rotor resistance, the fuzzy controllers calculate the new value and inject it into the control loop to ensure decoupling between the flux and torque dynamics.

Figure 11 shows the effect of a slow change of the rotor resistance on the flux behavior. Without adaptation it is clear that we will lose the direction of flux (Figure 11(a)). However, with rotor resistance adaptation we can keep the orientation of the flux (Figure 11(b)).

Figure 12 shows the response of the fuzzy controller for a slow variation of rotor resistance; the estimated and actual rotor resistances are almost the same.

Figure 13 represents the reference, estimated, and actual speed. This figure illustrates the speed system response under a load torque of $10 \mathrm{Nm}$ applied at $t=0.5 \mathrm{~s}$; the reference speed is increased from zero to its rated value $157 \mathrm{rd} / \mathrm{s}$. The motor reaches its steady state after $0.4 \mathrm{~s}$. At $t=1 \mathrm{~s}$, we applied a slow increase of $50 \%$ of the value of the rotor resistance and a change in the reference speed at $t=1.5 \mathrm{~s}$. The real and estimated speed are nearly similar and the difference between 


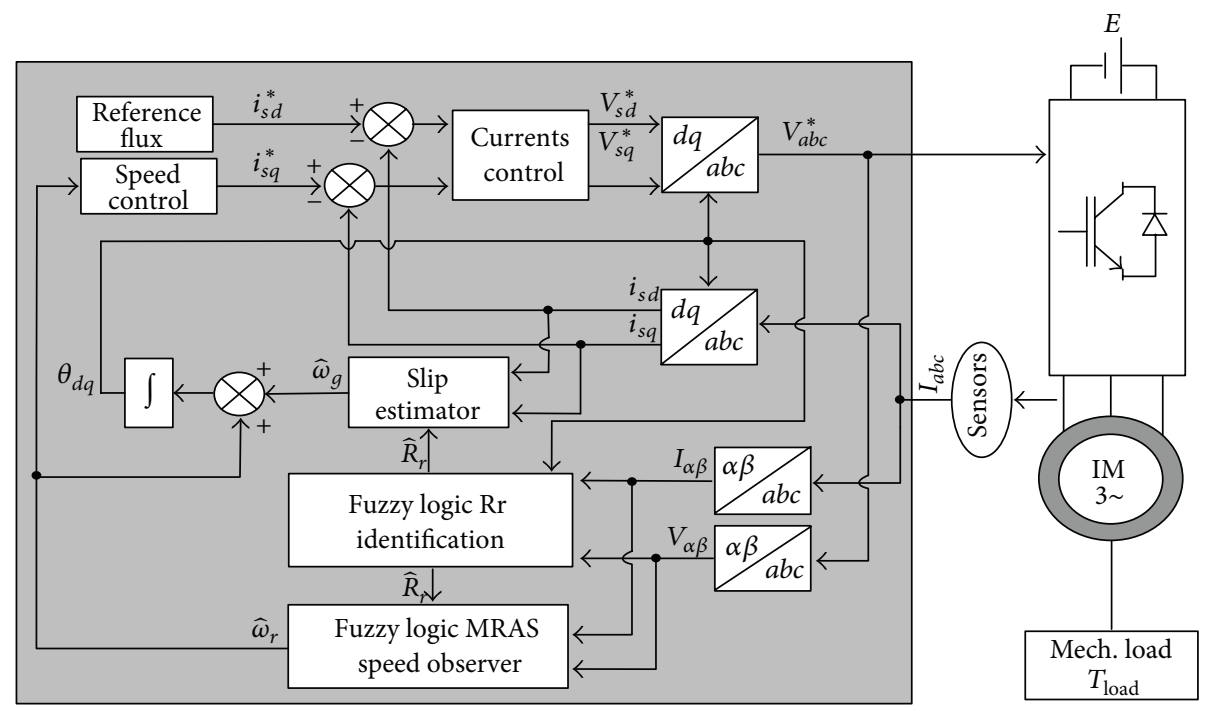

FIGURE 8: Block diagram of the vector control including speed and rotor resistance fuzzy logic observer.

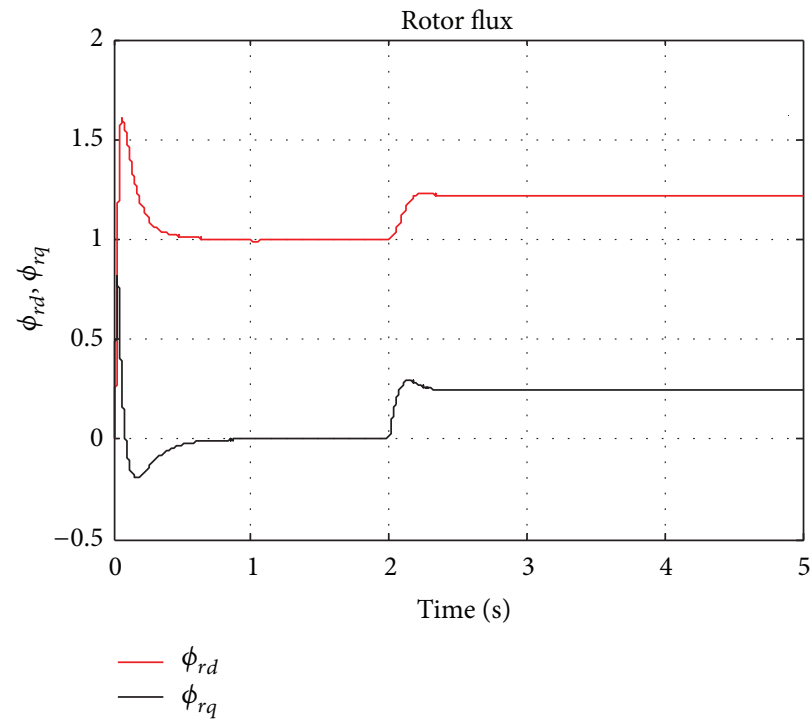

(a)

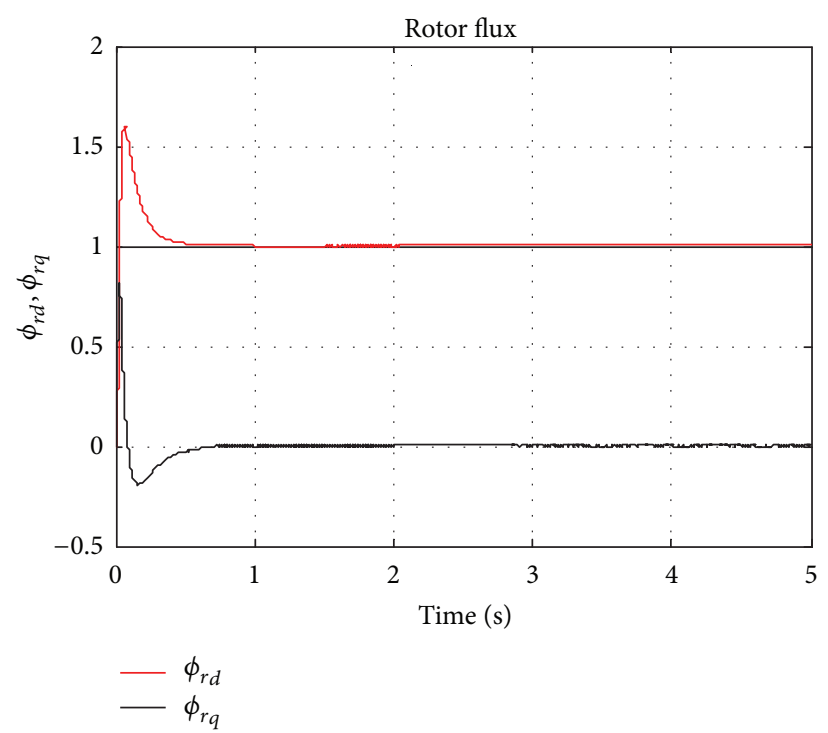

(b)

FiguRE 9: Simulated results with sudden change of the rotor resistance with and without adaptation: (a) without adaptation and (b) with adaptation.

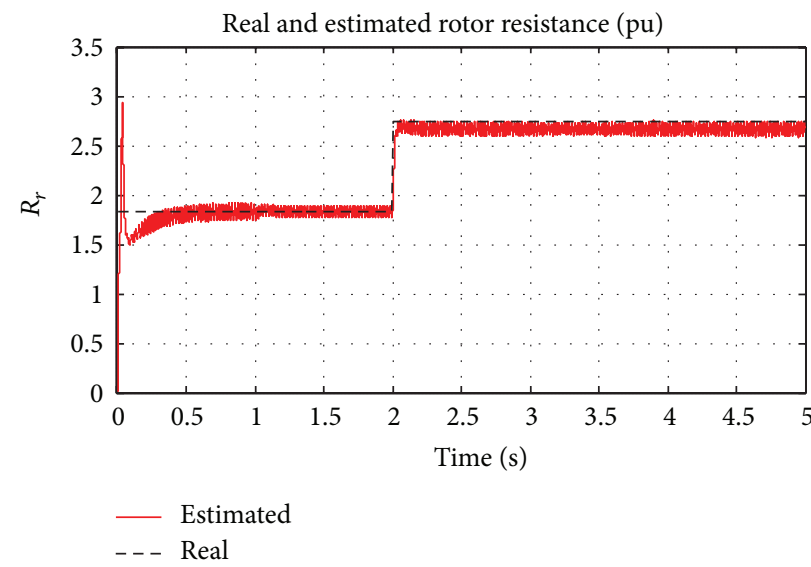

FIGURE 10: Tracking of the rotor resistance by fuzzy logic controller (case: sudden change). 


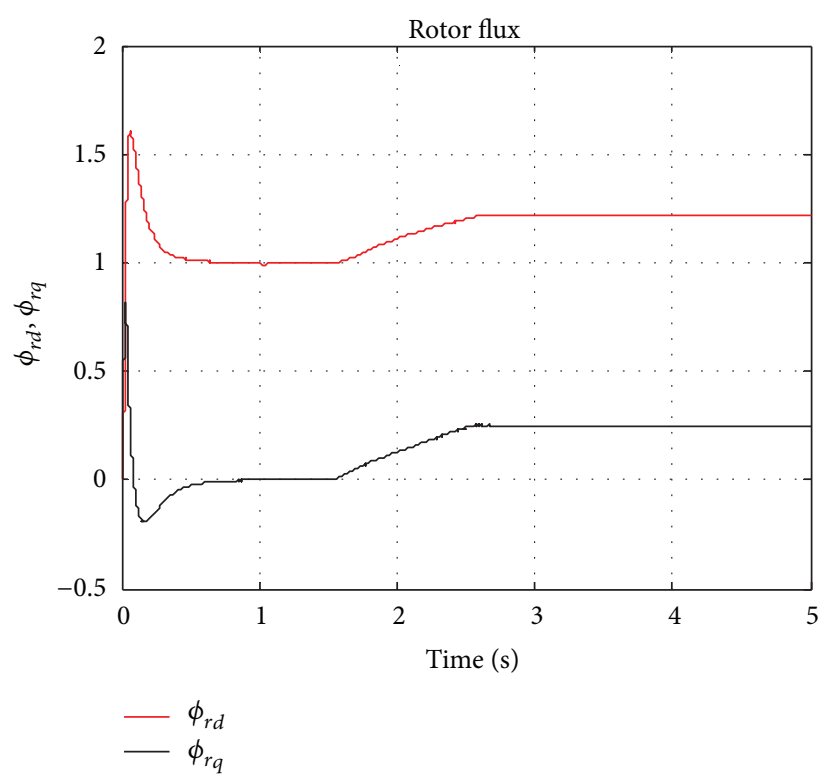

(a)

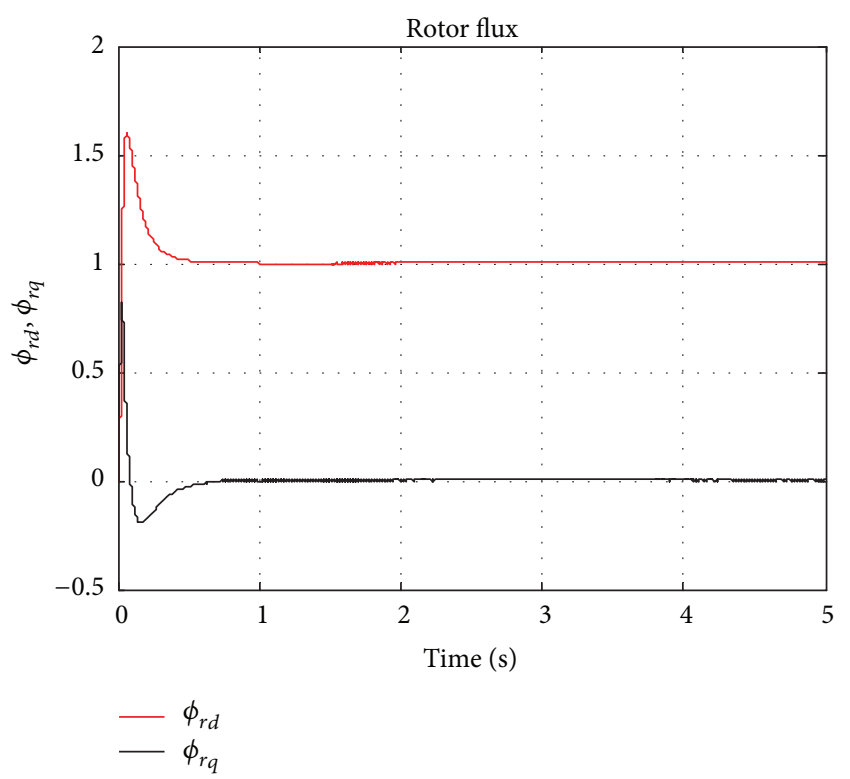

(b)

FIGURE 11: Simulated results with slow change of the rotor resistance with and without adaptation: (a) without adaptation, and (b) with adaptation.

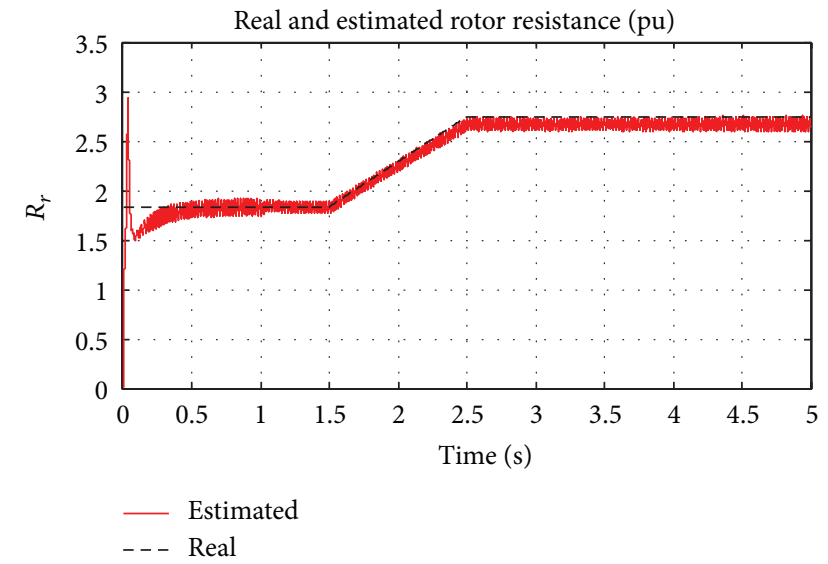

FIGURE 12: Tracking of the rotor resistance by fuzzy logic controller (case: slow change).

TABLE 3: Parameters of induction motor.

\begin{tabular}{lcc}
\hline Designation & Notations & Rating values \\
\hline Stator resistance & $R_{s}$ & $2.3 \Omega$ \\
Rotor resistance & $R_{r}$ & $1.83 \Omega$ \\
Stator self-inductance & $L_{s}$ & $261 \mathrm{mH}$ \\
Rotor self-inductance & $L_{r}$ & $261 \mathrm{mH}$ \\
Mutual inductance & $L_{m}$ & $245 \mathrm{mH}$ \\
Moment of inertia & $J$ & $0.03 \mathrm{kgm}^{2}$ \\
Friction coefficient & $f$ & $0.002 \mathrm{Nm}$ \\
Number of poles & $n_{p}$ & 2 \\
Rated voltage & $V_{s n}$ & $220 \mathrm{~V}$ \\
\hline
\end{tabular}

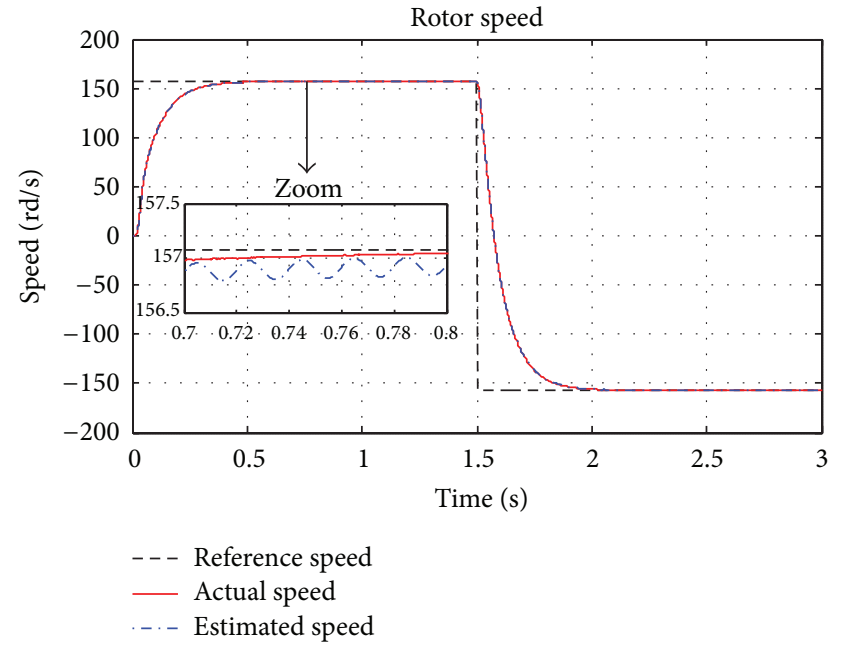

FIgURE 13: Simulation result of the fuzzy logic MRAS speed observer.

them is better shown in Figure 14 which does not exceed 1\% of the nominal value.

\section{Conclusion}

To sum up we say that this paper presents a method to estimate the rotor resistance for induction machines based on the theory of fuzzy logic. A standard IFOC without speed sensor has been used for the induction machine based on the same theory to design a MRAS speed observer. The modeling approach proposed for both observers makes a high-performance control strategy to be used with induction 


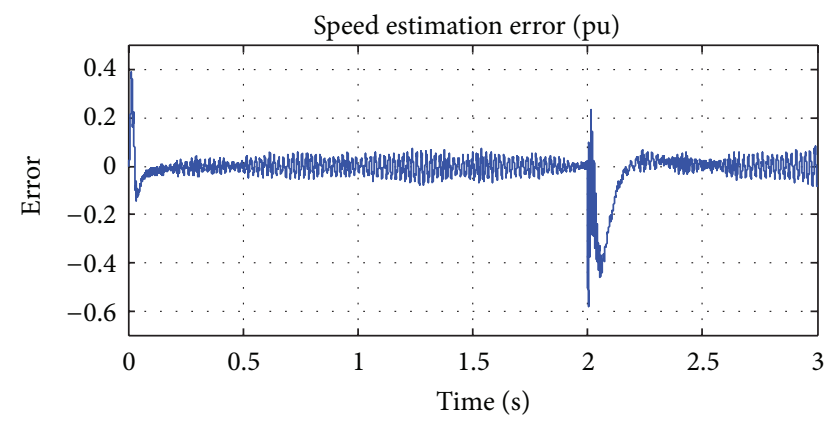

FIGURE 14: Error between real and estimated speed.

motor drive system. The drive system has been simulated with adaptive mechanisms to identify the values of rotor resistance and rotor speed based on fuzzy logic. The different simulation results have shown that the designed fuzzy logic observer has realized a good dynamic and performance for motor monitoring even in the case of the rotor resistance variation. The efficacity of the speed sensorless of the IFOC with rotor resistance is proved by extensive simulation results. The IFOC, the speed observer, and the rotor resistance observer described in the previous sections are to be implemented in the future work on a digital processor (DSP) to validate the proposed scheme.

\section{Conflict of Interests}

The authors declare that there is no conflict of interests regarding the publication of this paper.

\section{References}

[1] C. B. Regaya, A. Zaafouri, and A. Chaari, "Speed sensorless indirect field-oriented of induction motor using two type of adaptive observer," in Proceedings of the International Conference on Electrical Engineering and Software Applications (ICEESA '13), pp. 1-5, Hammamet, Tunisia, March 2013.

[2] F. Farhani, C. B. Regaya, A. Zaafouri, and A. Chaari, "Electric drive control: multi-level optimization efficiency," in Proceedings of the 4th International Renewable Energy Congress (IREC '12), pp. 894-898, Sousse, Tunisia, December 2012.

[3] C. B. Regaya, F. Farhani, A. Zaafouri, and A. Chaari, "Comparison between two methods for adjusting the rotor resistance," International Review on Modelling \& Simulations, vol. 5, no. 2, pp. 938-944, 2012.

[4] A. Savoia, C. M. Verrelli, M. Mengoni, L. Zarri, A. Tani, and D. Casadei, "Adaptive flux observer for induction machines with on-line estimation of stator and rotor resistances," in Proceedings of the 15th International Power Electronics and Motion Control Conference (EPE/PEMC '12), pp. LS7b-1.3-1LS7b-1.3-6, Novi Sad, Serbia, September 2012.

[5] G. Shuqiu and L. Zhongli, "Induction motor vector control based on adaptive identification of rotor resistance," in Proceedings of the International Conference on Control Engineering and Communication Technology (ICCECT '12), pp. 145-148, Liaoning, China, December 2012.

[6] Y. Miloud and A. Draou, "Fuzzy logic based rotor resistance estimator of an indirect vector controlled induction motor drive," in Proceedings of the 28th Annual Conference of the IEEE Industrial Electronics Society (IECON '02), vol. 2, pp. 961-966, Sevilla, Spain, November 2002.

[7] H. Zhang, Y. Shi, and J. Wang, "Observer-based tracking controller design for networked predictive control systems with uncertain Markov delays," International Journal of Control, vol. 86, no. 10, pp. 1824-1836, 2013.

[8] H. Zhang, Y. Shi, and A. S. Mehr, "On H-infinity filtering for discrete-time takagi-sugeno fuzzy systems," IEEE Transactions on Fuzzy Systems, vol. 20, no. 2, pp. 396-401, 2012.

[9] H. Kubota, I. Sato, Y. Tamura, K. Matsuse, H. Ohta, and Y. Hori, "Regenerating-mode low-speed operation of sensorless induction motor drive with adaptive observer," IEEE Transactions on Industry Applications, vol. 38, no. 4, pp. 1081-1086, 2002.

[10] H. M. Kojabadi, L. Chang, and R. Doraiswami, "A MRASbased adaptive pseudoreduced-order flux observer for sensorless induction motor drives," IEEE Transactions on Power Electronics, vol. 20, no. 4, pp. 930-938, 2005.

[11] T. Orlowska-Kowalska and M. Dybkowski, "Improved MRAStype speed estimator for the sensorless induction motor drive," COMPEL: The International Journal for Computation and Mathematics in Electrical and Electronic Engineering, vol. 26, no. 4, pp. 1161-1174, 2007.

[12] A. A. Adam and K. Gulez, "Fast response adaptive fuzzy logic controller for sensorless direct torque control of PMSM with minimum torque ripple," COMPEL: The International Journal for Computation and Mathematics in Electrical and Electronic Engineering, vol. 27, no. 2, pp. 534-550, 2008.

[13] R. P. Vieira, C. C. Gastaldini, R. Z. Azzolin, and H. A. Grundling, "Discrete-time sliding mode speed observer for induction machine drives," in Proceedings of the 11th Brazilian Power Electronics Conference (COBEP '11), pp. 213-218, Natal, Brazil, September 2011.

[14] D. Traoré, J. de Leon, and A. Glumineau, "Sensorless induction motor adaptive observer-backstepping controller: experimental robustness tests on low frequencies benchmark," IET Control Theory and Applications, vol. 4, no. 10, pp. 1989-2002, 2010.

[15] D. P. Marčetić and S. N. Vukosavić, "Speed-sensorless AC drives with the rotor time constant parameter update," IEEE Transactions on Industrial Electronics, vol. 54, no. 5, pp. 26182625, 2007.

[16] A. Larabi and M. S. Boucherit, "Robust speed-sensorless induction motor with the rotor time constant adaptation," in Proceedings of the International Conference on Electrical Systems for Aircraft, Railway and Ship Propulsion (ESARS '10), Bologna, Italy, October 2010. 


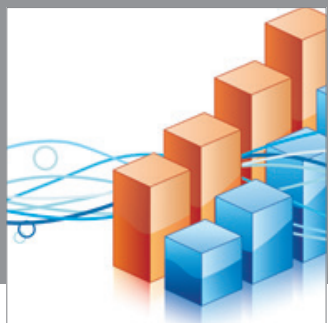

Advances in

Operations Research

mansans

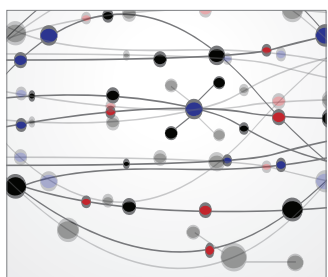

The Scientific World Journal
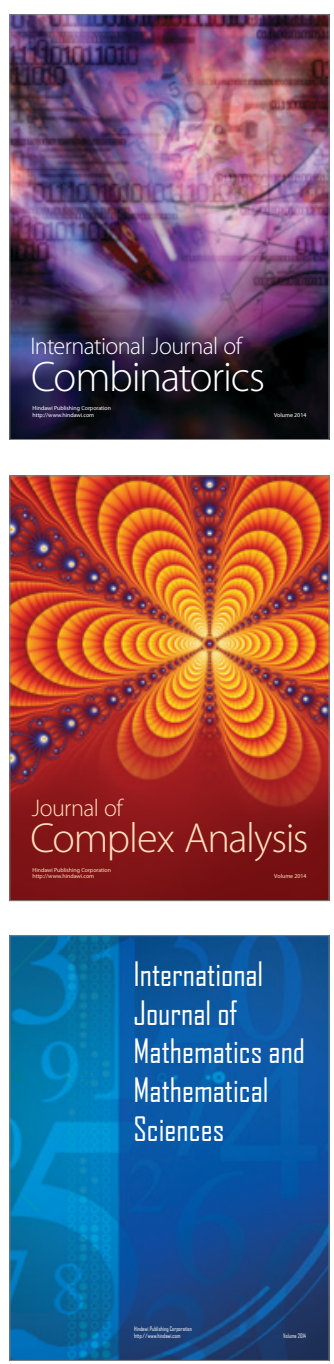
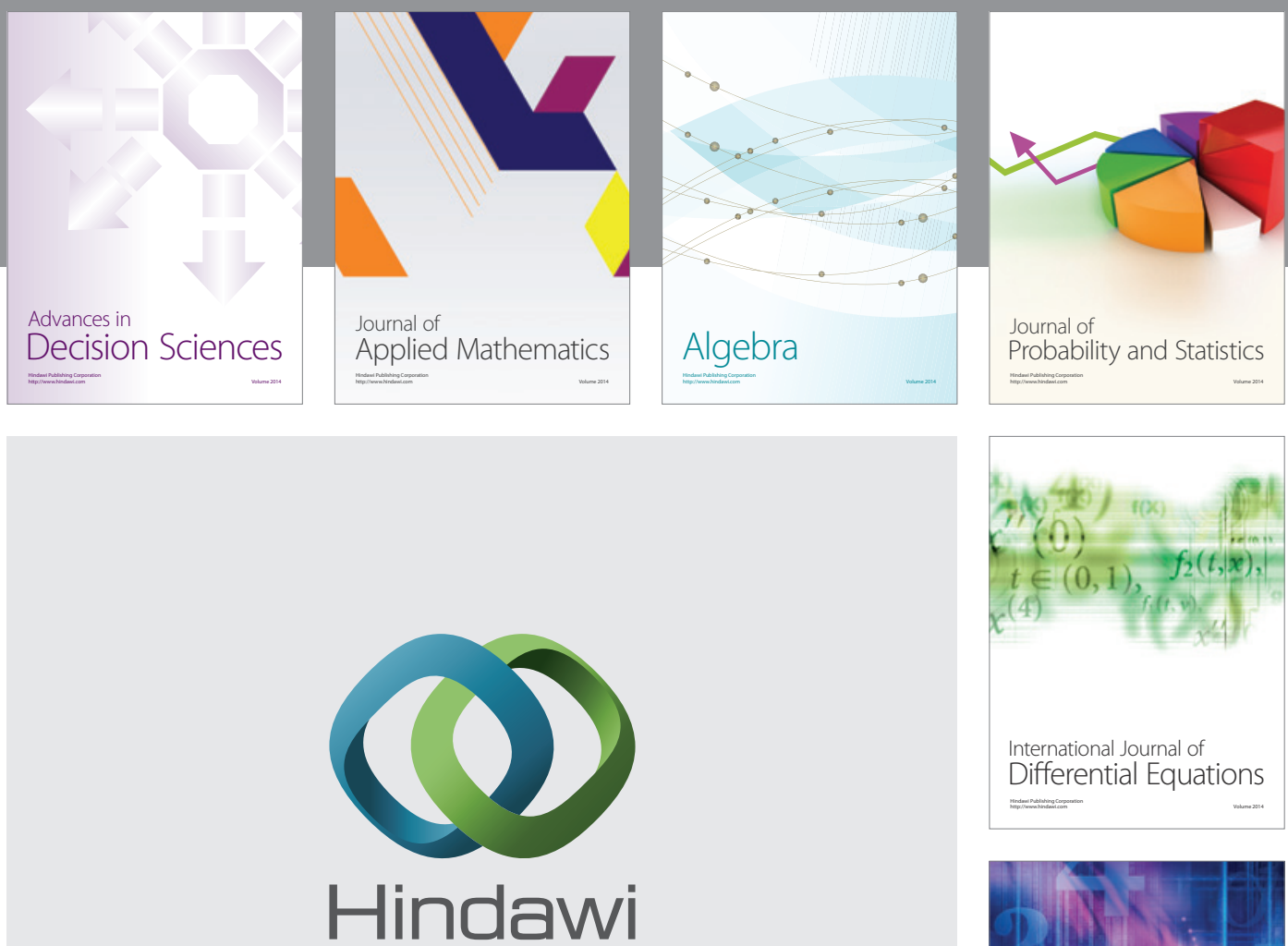

Submit your manuscripts at http://www.hindawi.com
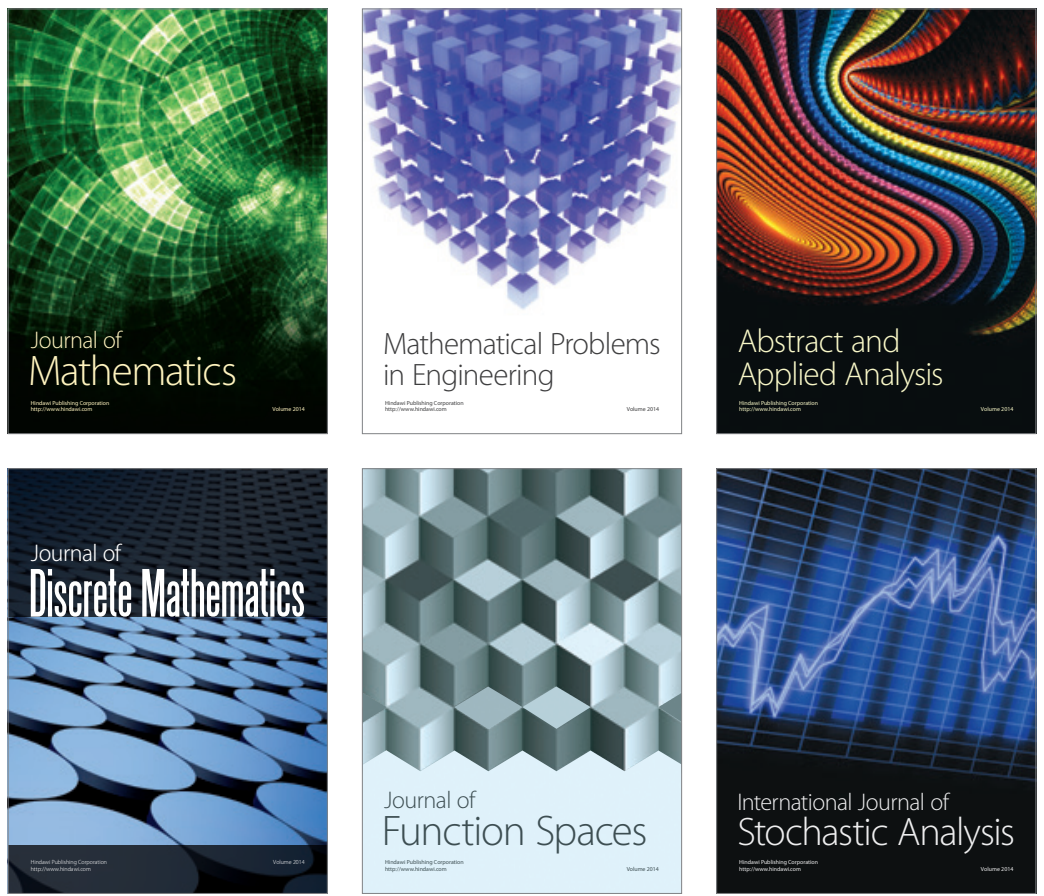

Journal of

Function Spaces

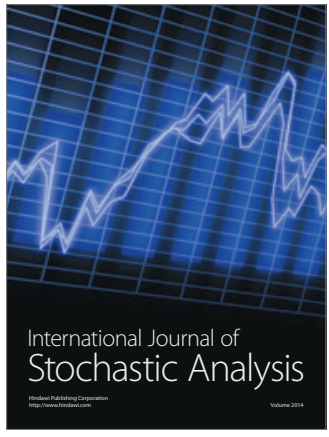

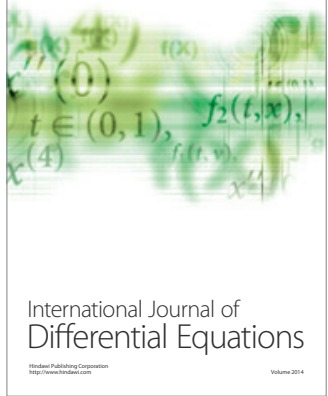
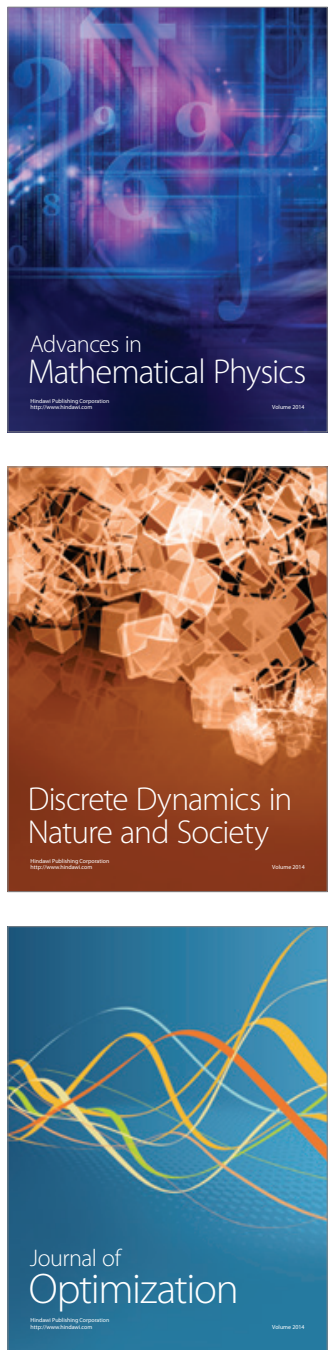